\title{
Sulfa Resistance in Mouse-Derived Pneumocystis carinii
}

\author{
BRIAN LANE, ${ }^{1}$ PAUL HOSSLER, ${ }^{1}$ MARILYN BARTLETT, ${ }^{2}$ SHERRY QUEENER, ${ }^{2}$ TERRY O'REILLY, ${ }^{3}$ JAMES SMITH, ${ }^{2}$ AND STEVEN \\ MESHNICK ${ }^{1, *}$ \\ ${ }^{1}$ Dept. of Epidemiology, Univ. of Michigan, Ann Arbor, MI, ${ }^{2}$ Dept. of Pathology and Lab. Medicine, Indiana University School of Medicine, Indianapolis. IN, \\ and ${ }^{3}$ Pharma Research. Ciba-Geigy. Basel, Switzerland
}

Sulfa drugs, such as sulfamethoxazole and dapsone, are pivotal for the prophylaxis and therapy of $P$. carinii pneumonia. Sulfa drugs act by inhibiting dihydropteroate synthetase (DHPS), an enzyme involved in de novo folate biosynthesis. In $P$. carinii, DHPS is part of a trifunctional protein, Fas, which has previously been cloned and sequenced from rat-derived organisms (1).

Sulfa resistance has developed in a variety of bacterial and protozoan pathogens. In most cases, resistance has been shown to be due to point mutations in the gene coding for DHPS. In order to investigate whether sulfa resistance mutations could occur in $P$. carinii, the DHPS coding sequence was PCR-amplified and sequenced from infected mice before, during and after exposure to several rounds of subtherapeutic doses of sulfa.

MATERIALS AND METHODS. Latently infected SCID mice were immunosuppressed as described (2). For each treatment cycle, mice were given trimethoprim/sulfamethoxazole $(25 / 125 \mathrm{mg} / \mathrm{kg})$ p.o. 5 times per week for 3 weeks. There were 4 treatment cycles. In between any two treatment cycles was a 3 week period without treatment. Mice were sacrificed before and after the experiment and the lungs were frozen.

Lung homogenates were then injected intratracheally into immunosuppressed germ-free mice (3). These mice were given sulfamethoxazole $(0.3 \mathrm{mg} / \mathrm{kg} / \mathrm{d})$ in their drinking water for 6 weeks and sacrificed. Lung homogenates from these mice were passaged one more time into immunosuppressed mice, this time administered sulfamethoxazole at $0.4 \mathrm{mg} / \mathrm{kg} / \mathrm{d}$. As a control for the latter passage, mice infected with the IU strain of $P$. carinii were also treated with sulfamethoxazole at $0.4 \mathrm{mg} / \mathrm{kg} / \mathrm{d}$. At the end of 6 weeks, both sets of mice were sacrificed and the degree of infection scored.

DNA was extracted from frozen lungs and PCR-amplified as previously described (4). Amplifed products were gel-purified and sequenced by dye-terminator automated sequencing.

RESULTS AND DISCUSSION. In order to ascertain whether the drug-treated organisms were resistant to sulfa, lungs were removed from treated and untreated mice and assessed for degree of infection (Table 1) (5). While mice infected with the IU strain demonstrated marked decreases in organism burden after treatment with sulfamethoxazole $(0.8$ vs 4.1$)$, mice infected with the $P$. carinii strainexposed to sulfa showed very poor responses to sulfa treatment $(2.2$ vs 3.5$)$. These data suggest that the treated organisms had developed resistance to sulfa.
Table 1. Effects of sulfamethoxazole on degree of infection in lungs

\begin{tabular}{|c|c|c|}
\hline \multirow[t]{2}{*}{$P$. carinii strain } & \multirow{2}{*}{\multicolumn{2}{|c|}{$\begin{array}{l}\text { Treated Untreated } \\
\text { (Giemsa score) }\end{array}$}} \\
\hline & & \\
\hline Drug & $2.2 \pm 0.24$ & $3.5 \pm 0.14$ \\
\hline IU strain & $0.8 \pm 0.24$ & $4.1 \pm 0.09$ \\
\hline
\end{tabular}

DHPS sequences were obtained from infected lungs before treatment, after initial treatment, after the first passage mice were sacrificed and after the second passage mice were sacrificed. All four sequences were $100 \%$ identical at the nucleotide level. The deduced amino acid sequence is shown in Figure 1 and is $94 \%$ idetnical to the sequence from rat-derived $P$. carinii. The DHPS nucleotide sequence from the treated strain, which was originally derived in Ciba-Geigy in Switzerland, was $100 \%$ identical to the DHPS nucleotide sequence from the IU strain (4) which has been maintained at Indiana University.

Continuous exposure of $P$. carinii-infected mice to subtherapeutic levels of sulfa appears to have led to the development of sulfa resistance. The resistance, however, was not due to a mutation within the coding sequence of DHPS. Thus, another mechanism of drug resistance appears to be responsible for the observed phenotype. Other possible mechanisms, including impaired drug accumulation, gene amplification and mutations on other positions in the Fas gene are now under investigation.

The relative stability of the DHPS in mouse-derived $P$. carinii contrasts starkly with recent evidence for polymorphisms within the DHPS from human-derived organisms (4). [Supported by NIH grants RO1-AI 31775, UO1-AI-35203 and NO1-AI-35171.]

1. Volpe F, Dyer M, Scaife JG, Darby G, Stammers DK, Delves CJ. Gene (1992) 112:213-218

2. Kunz S, Junker U, Blaser J, Joos B, Meyer B, Zak O, O'Reilly T J.Antimcrob. Chemother. (1995) 36:137-155.

3 Bartlett MS. Queener SF, Durkin MM, Shaw MA, Smith JW. Diagn. Microbiol. Infect. Dis. (1992) 15:129-134.

4. Lane BR, Ast JC, Hossler PA, Mindell DP, Bartlett MS, Smith JW, Meshnick SR. Submitted for publication.

Figure 1. Deduced amino acid sequence of $P$. carinii DHPS from untreated SCID mice and after exposure to sulfamethoxazole. Second line represents alignment with the DHPS from rat-derived $P$. carinii (1), showing only amino acid differences.

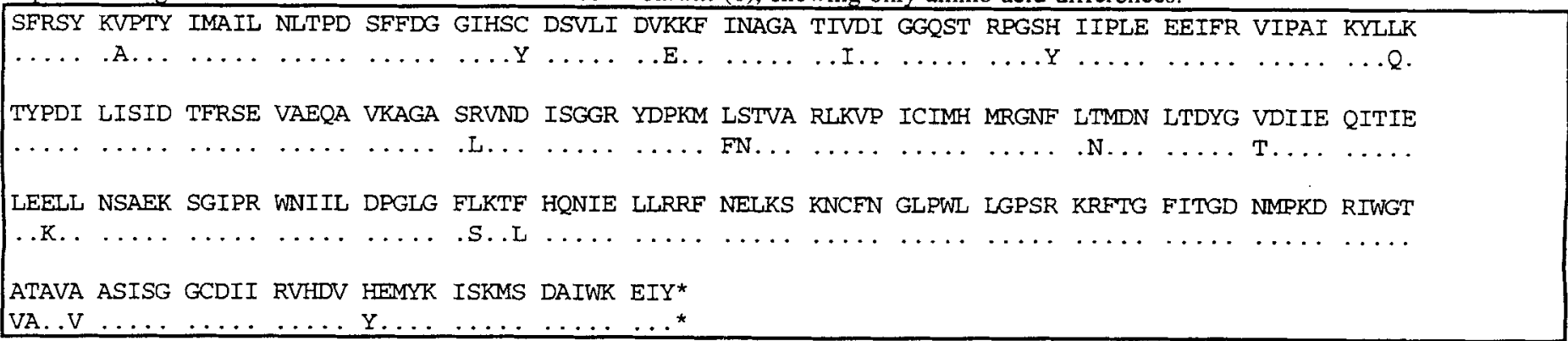

